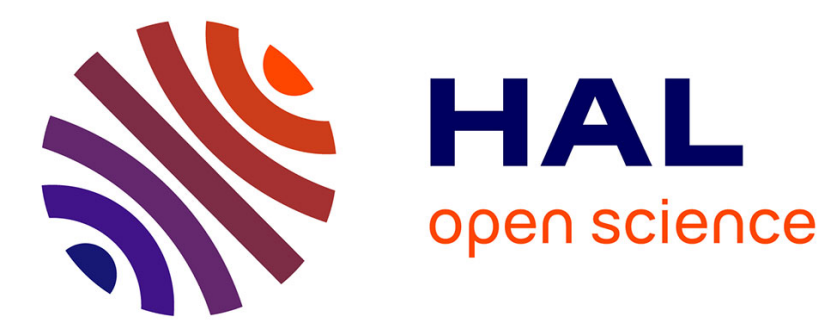

\title{
Mechanical and Tribological Behaviors of Nanocomposite Titanium Nitrides Coatings
}

Ahlam Belgroune, Linda Aissani, Faiza Salhi, Corinne Nouveau, Akram

Alhussein

\section{- To cite this version:}

Ahlam Belgroune, Linda Aissani, Faiza Salhi, Corinne Nouveau, Akram Alhussein. Mechanical and Tribological Behaviors of Nanocomposite Titanium Nitrides Coatings. Defect and Diffusion Forum (Online), 2021, 406, pp.312-318. 10.4028/www.scientific.net/ddf.406.312 hal-03133216

\author{
HAL Id: hal-03133216 \\ https://hal.science/hal-03133216
}

Submitted on 5 Feb 2021

HAL is a multi-disciplinary open access archive for the deposit and dissemination of scientific research documents, whether they are published or not. The documents may come from teaching and research institutions in France or abroad, or from public or private research centers.
L'archive ouverte pluridisciplinaire HAL, est destinée au dépôt et à la diffusion de documents scientifiques de niveau recherche, publiés ou non, émanant des établissements d'enseignement et de recherche français ou étrangers, des laboratoires publics ou privés. 


\title{
Mechanical and Tribological Behaviors of Nanocomposite Titanium Nitrides Coatings
}

\author{
Ahlam Belgroune ${ }^{1, a^{*}}$, Linda Aissani ${ }^{2, b}$, Faiza Salhi $^{2, \mathrm{c}}$, Corrine Nouveau $^{3, \mathrm{~d}}$ \\ and Akram Alhussein ${ }^{4}$ \\ ${ }^{1}$ Laboratory of Active Components and Materials, Larbi Ben M'Hidi. University, Oum El Bouaghi \\ 04000, Algeria. \\ ${ }^{2}$ Department of matter sciences, ABBESL Aghrour University, Khenchela. P. O 1252, 40004, \\ Algéria. \\ ${ }^{3}$ La.Bo.Ma. P, ENSAM, Rue Porte de Paris, 71250 Cluny, France. \\ ${ }^{4}$ ICD - LASMIS. University of Technology of Troyes. Antenned of Nogent. Pôle Technological pole \\ of Sud-Champagne 26, Lavoisier - 52800 Nogent. France. \\ aahlam.belgroune@gmail.com, bLindaaissani2004@yahoo.fr, cfaiza.salhi@gmail.com \\ dCorinne.ouveau@ensam.fr, eakram.alhussein@utt.fr
}

Keywords:TiN, Nanocomposite coating, Mechanical property, Friction, Wear,

\begin{abstract}
TiN coatings with a thickness of $2 \mu \mathrm{m}$ were deposited using the magnetron sputtering has developed rapidly over the last decade in such a way that it has become an established process of choice for the deposition of a wide range in various applications for different domains as it gives excellent performance in many aspects. In view of this, we have deposited the TiN coatings by magnetron sputtering using Ti target at different nitrogen content to study the influence of the nitrogen content on the mechanical properties and tribological behaviors of the TiN coatings were systematically investigated using nanoindentation and a pin-on-disk tribometer. Nanoindentation results shows that the hardness and Young's modulus of the TiN coatings increase with increasing $\mathrm{N}$ content in the coatings.

Wear test results indicate that the wear rate and friction coefficient of the XC100 steel substrate were significantly reduced by deposition of the TiN coatings, and the tribological behaviors of the TiN coatings are strongly dependent on the nitrogen content in the coatings.
\end{abstract}

\section{Introduction}

The fast growing surface engineering research today could be explained by the high industrial demands for desirable mechanical properties as well as tribological performance; to prevent tools deterioration under severe conditions, such as drilling, milling or cutting where protective coatings are the best solution fond [1,2].

Transition metal based nitrides like $\mathrm{TiN}, \mathrm{ZrN}$, TaN and $\mathrm{CrN}$ coatings are applied on of metallic substrates used in numerous applications; automobile parts also as wear resistant coatings for cutting tools coatings, bio-implants, and decorative coating [1,3].

TiN received a great attention in the resent years, where researches confirmed that titanium nitride can improve corrosion and wear resistant, and lifetime of the materials up to 400\% [3] thanks to its high hardness, high thermal stability, low electrical resistivity, high wear and excellent corrosion resistance chemical stability and biocompatibility, adding the interesting optical properties [4,5].

The physical and tribological properties of the sputter-deposited films was found to have a strong correlations with the deposition parameters [6] for example; the substrate temperature has strong effects on the lattice constant of TiN grown in $\mathrm{Ar}-\mathrm{N}_{2}$ mixed gas. As the substrate temperature increases, there is an increase in the adatomes mobility of the sputtered species on the substrate and increasing in the crystal size [4]. 
There are several techniques to prepare TiN thin films such as physical vapor deposition (PVD) [7], chemical vapor deposition (CVD) [8], thermal spraying [9] and ion implantation [10]. Among them, magnetron sputtering has specific advantages, such as low deposition temperature, large deposition area, low impurity level, high deposition rates, and superior bonding strength $[11,12]$.

D.G. Constantin et al. [13] deposited by direct current magnetron sputtering TiNx thin films onto high-speed steel, silicon and stainless steel substrates, from a pure Ti target, varying the flow rate of the reactive gas, a crystalline structure with fcc phase and strong (111) orientation of the peaks, obtained using the lowest nitrogen gas flow of $4.5 \mathrm{sccm}$ and the most performing TiNx film was that one with small sized of the grains (around $8 \mathrm{~nm}$ ), a higher value of hardness (18.4 GPa) and a good thickness of $1.5 \mu \mathrm{m}$ were obtained also.

Using a gas mixture ratio $\mathrm{Ar}-\mathrm{N}_{2} 10$ and $12 \%$ of $\mathrm{N}_{2}$ and power density from 7.4 to $10.8 \mathrm{~W} \mathrm{~cm}^{-2}$ by pulsed dc magnetron sputtering, C. I. Enriquez-Flores et al. studied the microstructural and mechanical properties of titanium nitride (TiN) films. It was reported that the hardness increases when the $\Phi$ e increases where a significant increment in the (110) orientation growing plane obtained by the TiN films with high hardness and the smallest grain size. The films exhibit a nanostructure of elastic domains, being the principal elastic domain of $270 \mathrm{GPa}[14]$.

More recently M.A. DomínguezCrespo et al. deposited by R.f. magnetron sputtering on AISI 316L SS different Ti/TiN coatings in order to study the effect of sputtering conditions on tribological and corrosion properties. The cross section of scanning electron microscopy and profilometer measurements indicate an average film thickness between 320 and $860 \mathrm{~nm}$ in dependence of the sputtered parameters, the largest increase in hardness was from $\sim 5$ to $\sim 20 \mathrm{GPa}$ with a friction coefficient $(\mu)$ that varies from 0.012 to 1.3 . Power and substrate temperature played the most important role in the final properties of Ti/TiNbilayered coatings [15].

E. Ajenifuja et al, sputtered with different thicknesses of TiNx thin film with varying time from 5 to $20 \mathrm{~min}$, using DC reactive magnetron sputtering technique. While other process parameters were kept constant during the deposition, the deposition. The optimum value of the Vickers hardness was found to be 267.9 for the film deposited at $20 \mathrm{~min}$. The inter-planar spacing was found to be from $2.0362 \AA$ to $2.0890 \AA$, while corresponding lattice parameter was calculated to be from $4.0724 \AA$ to $4.1780 \AA$. Scanning electron microscopy observation of the films gave an indication of fine-grained microstructure, which confirms the good adhesion and hardness properties of titanium nitride layer on the LCS substrate where the changes in crystal orientations of the TiNx films with deposition time. Ion beam (RBS) results showed increase in amount of nitrogen contents (47-64\%) in TiNx films with thickness and deposition time. [16].

In this paper we have therefore studied the mechanical and tribological behaviors titanium of nitrides coatings deposited on XC100 steel by magnetron sputtering at different nitrogen partial pressures. The structures of TiN films are analyzed by (XRD), the surface morphology of the coatings isobserved using a SEM and AFM for surface roughness. The friction and wear performances of the as-deposited films are testedas well the mechanical properties are measured for different mixture gaz Ar- $\mathrm{N}_{2}$.

\section{Experimental}

The TiN films were deposited on XC100substrates by the magnetron sputtering technique (NORDIKO type 3500). TiN films were obtained by sputtering of titanium Target (99, $8 \%$ of purity) tin an argon and nitrogen atmosphere. The deposit parameters have been summarized in Table I.

The substrates were all ground, polished, ultrasonic cleaned and dried by air before put into the vacuum chamber. 
Table 1. Operating conditions for the deposit of tin obtained by sputtering magnetron R. F.

\begin{tabular}{|l|l|}
\hline Ar, $\left.\mathbf{N}_{2}\right)$ Pourcentage & $\begin{array}{l}(95 \%, 5 \%),(90 \%, 10 \%),(85 \%, 15 \%), \\
(80 \%, 20 \%),(75 \%, 25 \%)\end{array}$ \\
\hline Voltage & $-900[\mathrm{~V}]$ \\
\hline Target distance to substrat & $80[\mathrm{~mm}]$ \\
\hline Applied Power & $550[\mathrm{~W}]$ \\
\hline Time & $120[\mathrm{mn}]$ \\
\hline Pressure & $0.4[\mathrm{~Pa}]$ \\
\hline $\begin{array}{l}\text { Target pickling and substrate: } \\
\text { XC100 }\end{array}$ & $5[\mathrm{mn}]$ \\
\hline
\end{tabular}

The phase and crystal structure of the as-deposited films are identified by X-raydiffraction (Diffractometer SIEMENS type D500/501» in the continuous scanning mode with $\mathrm{Cu}-\mathrm{K} \alpha$ radiation $(\lambda=0.15406 \mathrm{~nm})$, for the surface morphologies we used the scanning electron microscope (SEM-Joel JSM-6400F, $10 \mathrm{kV}$ ), the film surface roughness was measured by atomic force microscopy (AFM. 100. APE research).

In order to To determine the value of hardness we used the Nanoindenteur MTS- XP, in the tribological behavior study we used a Scratch Tester Millenium 200, in order to trace the damage (wear) and a tribometer in plan point to determine the friction coefficient dring the sliting test.

\section{Results and Discussion}

\section{A. Microstructures of the TiN coatings}

From Table II, we obtain the nitride the Hexagonal phase $\mathrm{Ti}_{2} \mathrm{~N}$ from the percentage of nitrogen in plasma $\left(15 \% \mathrm{~N}_{2}\right)$ corresponding to a ratio $(\mathrm{N} / \mathrm{Ti}=0.62)$ also we noticed that the $\mathrm{Ti}_{2} \mathrm{~N}$ is not detected by the DRX at 5 and $10 \% \mathrm{~N}_{2}$ with ratio of 0.213 and 0.518 respectively On the other hand, at $20 \%$ $\mathrm{N}_{2}$, a mixture of phases $\left(\mathrm{Ti}_{2} \mathrm{~N}\right.$ and $\left.\mathrm{TiN}\right)$ is formed. Indeed, the Cubic TiN Phase is crystallized at $20 \% \mathrm{~N}_{2}$ with ratio $(\mathrm{N} / \mathrm{Ti}=1.01)$.

Table 2. Operating conditions for the deposit of tin obtained by sputtering magnetron R. F.

\begin{tabular}{|l|l|l|l|}
\hline $\mathbf{\%} \mathbf{N}_{2}$ & $\mathbf{N} / \mathbf{T i}$ & Thickness [nm] & Phases \\
\hline $\mathbf{5}$ & 0.213 & 960 & $\mathrm{Ti}$ \\
\hline $\mathbf{1 0}$ & 0.518 & 950 & $\mathrm{Ti}$ \\
\hline $\mathbf{1 5}$ & 0.621 & 945 & $\mathrm{Ti} 2 \mathrm{~N}$ \\
\hline $\mathbf{2 0}$ & 1.010 & 930 & $\mathrm{Ti}_{2} \mathrm{~N}+\mathrm{TiN}$ \\
\hline $\mathbf{2 5}$ & 1.171 & 920 & $\mathrm{Ti} \mathrm{N}$ \\
\hline
\end{tabular}

We can induce that there is a difference between the ratios (N/Ti) for the formation of various phases: like the $\mathrm{Ti}_{2} \mathrm{~N}$ phase, which appears at only $15 \% \mathrm{~N}_{2}$ (corresponding to $\mathrm{N} / \mathrm{Ti}=0.62$ ) instead of $10 \% \mathrm{~N}_{2}$ (corresponding to $\mathrm{N} / \mathrm{Ti}=0.518$ ), this can be explained by the high oxygen concentration in the deposited coatings which interferes with the incorporation of nitrogen into Ti. Other hand, we observe a progressive increase of residual stresses with increasing nitrogen content. And we can said that the low residual stress in the case of Ti rich layers: $\left(\% \mathrm{~N}_{2} \leq 5\right)(-0.4 \mathrm{GPa})$ and close to those of pure Ti.

At $15 \% \mathrm{~N}_{2}$ corresponding to the formation of $\mathrm{Ti}_{2} \mathrm{~N}$, the stresses increase and become ( $\left.\sigma=-1 \mathrm{GPa}\right)$, and finally these stresses reach their maximum $(\sigma=-1.1 \mathrm{GPa})$, when the nitrogen percentage reaches $20 \%$ corresponding to the predominant nitride $\mathrm{TiN}$ with a ratio $\mathrm{N} / \mathrm{Ti} \approx 1$. 


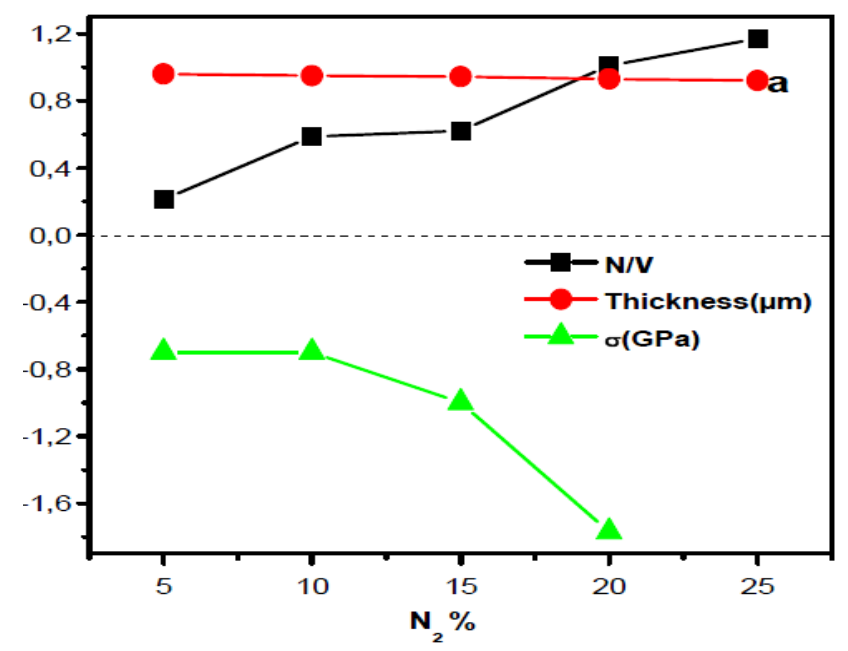

Fig. 1. Evolution of film thickness, stresses and $\mathrm{N} / \mathrm{Ti}$ ratio of the Ti-N layers as a function of the percentage of nitrogen in the plasma.

To show the morphology of these nitrides, Figure 2 presents a (SEM and AFM) image of TiN film (at $20 \% \mathrm{~N}_{2}$ ). According to this figure, the surface presents a rough and compact consisting of acute agglomerations of various sizes $(\mathrm{RMS}=70 \mathrm{~nm})$. A cross-sectional image presents a compact and columnar structure.
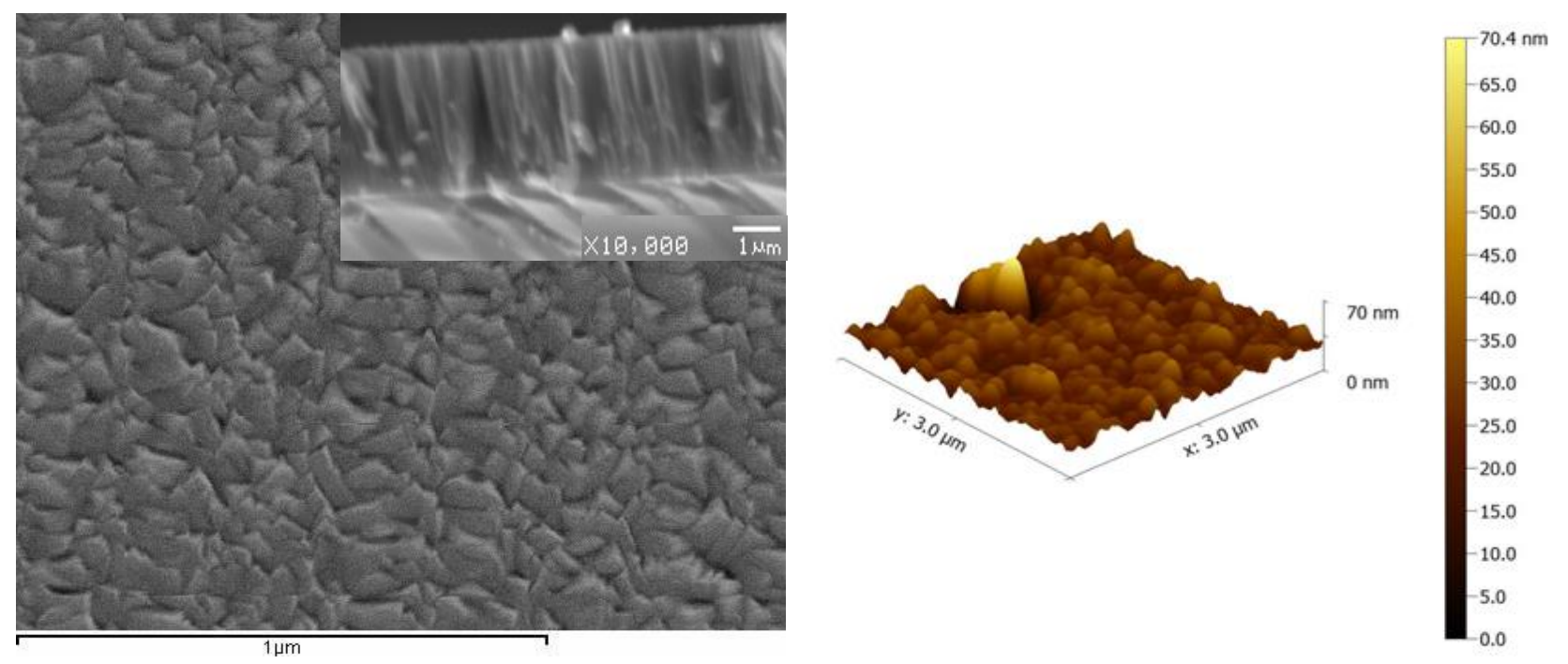

Fig. 2. SEM (a) and AFM (b) surface morphology of TiN thin film deposited with the $\mathrm{Ar} / \mathrm{N}_{2}$ ration 1:1.

\section{B. Mechanical properties of Titanium nitrides}

Figure 3 presents the evolution of hardness and the Young's modulus curves of titanium nitrides as a function of the nitrogen percentage in plasma. Between ( 5 to $10 \% \mathrm{~N}_{2}$ ), we observed that the hardness increases from 6 to $13 \mathrm{GPa}$; on the other hand, the Young's modulus remains constant over this range about $270 \mathrm{GPa}$ because of the rapid incorporation of nitrogen into Ti before stoichiometry. At $\left(15 \% \mathrm{~N}_{2}\right)$ a decrease in hardness and Young's modulus $(8 \mathrm{GPa}$ and $250 \mathrm{GPa})$ was observed. And from $20 \% \mathrm{~N}_{2}$, the low elasticity of the TiN layers can be explained by the surface roughness, which influences the measurements by nanoindentation. 


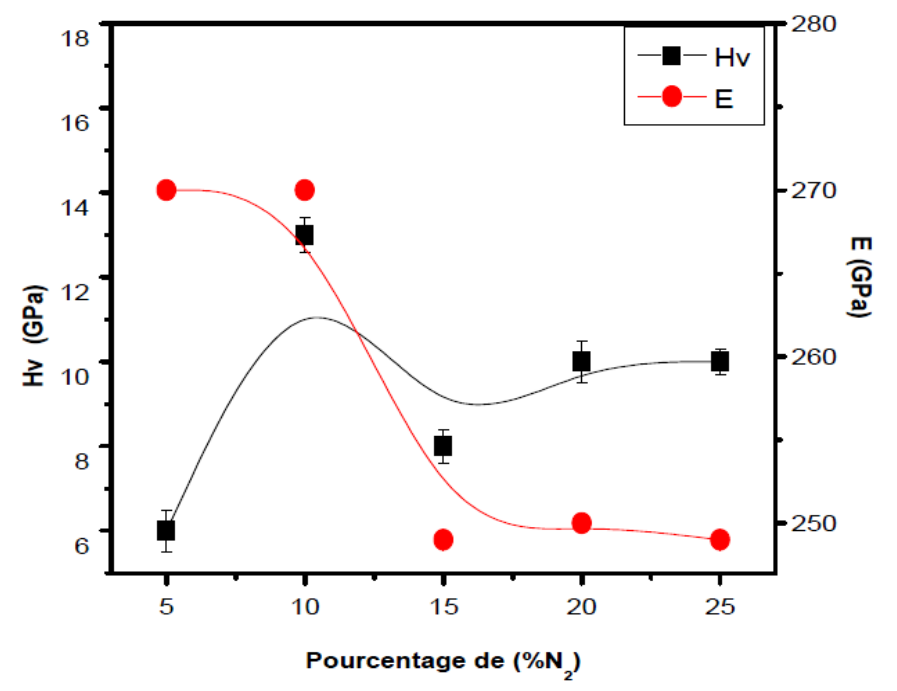

Fig. 3. Hardness and Young's modulus evolution for different percentage nitrogen in plasma.

\section{Tribologicalbehaviourlor}

We have shown that in figure 4, the evolution of the friction coefficient of the coatings ( $\mathrm{Ti}$, TiN and $\mathrm{Ti}_{2} \mathrm{~N}$ ) as a function of the sliding distance.

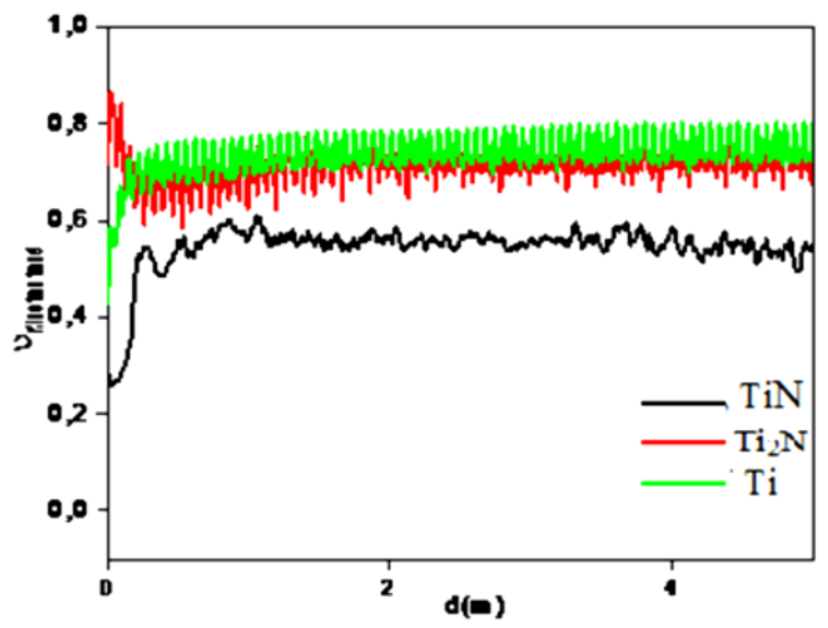

Fig. 4. Evolution of friction coefficient of the Ti-N films as a function of the slip distance.

During the test of the pure Ti film, we note that the recorded coefficient of friction stabilizes around 0.72 with a noise of 0.134 of width. This predicts a high wear which can be explained by the existence of an excess of defects in the Ti film. For the TiN film, we notice during the test a noise that was heard up to $2 \mathrm{~m}$ of wear track and the coefficient of friction stabilizes at a very low value of 0.50at $20 \%$ of $\mathrm{N}_{2}$ and then increases rapidly to 0.72 .

For the Ti-N films deposited at 10 and $20 \%$ of $\mathrm{N}_{2}$ flow rate, it can be seen that the wear resistance of the hard Ti-N coatings was higher than that of the other coatings. The best wear resistance of Ti$\mathrm{N}$ coating with high nitrogen content is closely related not only to the N/Ti ratio, but also to the morphology and structure of TiN films. A dense and smooth surface has less asperity or crevices as compared to porous coatings which result in better interlocking and adhesion. On the other hand, the coating deposited at $20 \%$ of $\mathrm{N}_{2}$ was found to achieve the desired combination of hardness (15 GPa). However, for the films deposited at higher nitrogen flow rate $(10 \%)$, there was more debris along the edges of the track, due to the weak substrate-film cohesion (Fig. 5 a). 

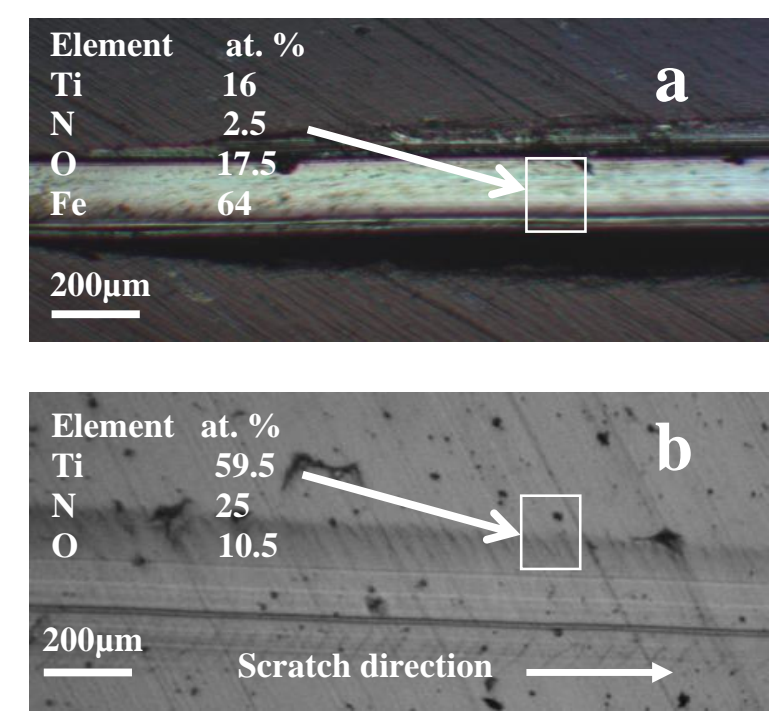

Fig. 5. Micrographs of scratch tracks performed on the Ti-N coatings deposited at: a) $10 \% \mathrm{~N}_{2}$, b) $20 \% \mathrm{~N}_{2}$

\section{Conclusion}

TiNx thin films were produced by magnetron sputtering. The thin films were deposited onto XC100 substrates, from a pure Ti target, varying the mixture gaz Ar- $\mathrm{N}_{2}$, We systematically clarify the effects of sputtering gas on the mechanical and tribological behaviors of TiN thin films.

We have shown that the formation of the cubic TiN phase corresponds to $\mathrm{N} / \mathrm{Ti}=1$ for $20 \% \mathrm{~N}_{2}$ and has compressive stresses of $-1.07 \mathrm{GPa}$, for $\mathrm{Ti}_{2} \mathrm{~N}$ phase of the ratio $\mathrm{N} / \mathrm{Ti}=0.62$ for $15 \% \mathrm{~N}_{2}$ has a compressive stresses of $-1 \mathrm{GPa}$ with contaminated coatings, moreover the TiN layers have a columnar structure with a rough and less dense surface, also it have the superior mechanical and tribological properties compared with those of the $\mathrm{Ti}_{2} \mathrm{~N}$ film.

\section{References}

[1] K.V. Chauhan, Sushant K. Rawal, A review paper on tribological and mechanical properties of ternary nitride based coatings. J. Procedia Technol. 14(2014) 430-437.

[2] D.G. Constantin, D. Munteanu, The influence of nitrogen Content on the mechanical Properties of tinxthin films Prepared by reactive magnetron Sputtering. Bulletin of the Transilvania. jEng Sci. 5(2012) 60-64.

[3] M.A. Domínguez-Crespo, A.M. Torres-Huerta, E. Rodríguez, A. Gonz_alez-Hern_andez, S.B. Brachetti-Sibaja, H.J. Dorantes-Rosales, A.B. L_opez-Oyama, Effect of deposition parameters on structural, mechanical and electrochemical properties in Ti/TiN thin films on AISI 316L substrates produced by r. f. magnetron sputtering, J. Alloys and Comp 746 (2018) 688-698.

[4] M. T. Hosseinnejad, M. Ettehadi-abari, N. Panahi, M. A. Ferdosizadeh, S. W. CASE, Structural, morphological and mechanical hardness properties of titanium nitride thin films deposited by DC magnetron sputtering: Effect of substrate temperature. J. OptoandAdvaMater19(5-6)(2017) 434-439.

[5] M.R. Chavdaa, D.P. Daveb, K.V. Chauhanb, S.K. Rawal, Tribological Characterization of TiN Coatings prepared by Sputtering. Procedia Technology 23 (2016) 36-41.

[6] N.Jianga, H.J. Zhanga, S.N. Baoa, Y.G. Shenb, Z.F. Zhou, XPS study for reactively sputtered titanium nitride thin films deposited under different substrate bias. Physica B 352 (2004) 118126. 
[7] W. Ming, M. Guojia, L. Xing, D. Chuang, Morphology and Mechanical Properties of TiN Coatings Prepared with Different PVD Methods, J. Rare Metal Mater and Eng. 45(12) (2016)3080-3084.

[8] J. Piippo, B. Elsener, H. Böhni, Electrochemical characterization of TiN coatings. J. Surf Coat Technol. 61(1993) 43-46.

[9] V.A. Şerban, R.A. Roşu, A.I. Bucur,D.R. Pascu,Deposition of titanium nitride layers by electric arc reactive plasma spraying method. J. Appl Surf Sci. 265 (2013) 245-249

[10] N. Huang, G.J. Wan, Y.Leng, Y.X. Leng, H. Sun, P. Yang, J.Y. Chen, J. Wang, P.K. Chu, Deformation behavior of titanium nitride film prepared by plasma immersion ion implantation and deposition, J. Surf Coat Technol. 156 (2002) 170-175.

[11] S. Zhang, F. Yan, Y. Yang, M. Yana, Y. Zhang, J. Guo, H. Li, Effects of sputtering gas on microstructure and tribological properties of titanium nitride films. J. Appl Surf Sci 488 (2019) 61-69.

[12] R. Banerjee, R. Chandra, P. Ayyub, Influence of the sputtering gas on the preferred orientation of nanocrystalline titanium nitride thin films. J. Thin Sol Films. 405 (2002) 64-72.

[13] D.G. Constantin, D. Munteanuthe, Influence of Nitrogen content on The mechanical properties of $\mathrm{TiN}_{\mathrm{x}}$ thin films prepared by reactive magnetron Sputtering. Bulletin of the Transilvania University of Braşov Series I. 5 (54) (2012).

[14] C. I. Enriquez-Flores, E. Cruz-Valeriano, A. Gutierrez-Peralta, J. J. Gervacio- Arciniega, E. Ramírez-Álvarez, E. Leon-Sarabia\& J. Moreno-Palmerin, Relation betweenwork function, microstructural and mechanical properties of TiN-films, Surface Engineering,34(9) (2017)1-7.

[15] M.A. Domínguez-Crespo, A.M. Torres-Huerta, E. Rodríguez, A. Gonz_alez-Hern_andez, S.B. Brachetti-Sibaja, H.J. Dorantes-Rosales, A.B. L_opez-Oyama, Effect of deposition parameters on structural, mechanical and electrochemical properties in $\mathrm{Ti} / \mathrm{TiN}$ thin films on AISI 316L substrates produced by r. f. magnetron sputtering, J. Alloys and Comp 746 (2018) 688-698.

[16] E. Ajenifuja, A. Patricia, I. Popoola, O.M. Popoola Thickness dependent chemical and microstructural properties of DC reactive magnetron sputtered titanium nitride thin films on low carbon steel cross-section. Mater res technol .8(1) (2019)377-384. 